\title{
The Current Status of Research on Geomagnetic Navigation in Pacific Salmon
}

\author{
Nathan F. Putman', Hiroshi Ueda ${ }^{2}$, and David L.G. Noakes ${ }^{3,4}$ \\ ${ }^{1}$ LGL Ecological Research Associates, 4103 South Texas Ave., Suite 211, Bryan, Texas 77802, USA \\ ${ }^{2}$ Hokkaido University/Hokkaido Aquaculture Promotion Corporation, Sapporo, Hokkaido 063-0813, Japan \\ ${ }^{3}$ Oregon State University, Department of Fisheries and Wildlife, Corvallis, Oregon 97331, USA \\ ${ }^{4}$ Oregon Hatchery Research Center, Alsea, Oregon 97324, USA
}

Keywords: magnetic map, orientation, sensory ecology, movement ecology, migration

From a human's perspective, the navigational task of ocean migrants is daunting: the open sea is vast, featureless, and in constant motion. Yet, numerous species transit ocean basins with seeming ease (Gould and Gould 2012). The migratory life-cycle is common and often includes use of spatially-restricted reproductive sites, dispersal of offspring, and eventual homing to the natal site to reproduce (Fig. 1). The life-history strategy is remarkably effective; indeed, many of the world's most important fisheries take advantage of the large numerical abundance and biomass that results (Secor 2015). The migrations of animals thus require efficient and directed movements between or among distant habitats (Fig. 1). Animal navigation can be likened to a two-step process, the "map step" whereby the animal assesses where it is relative to some goal and the "compass step" whereby the animals maintains a heading in the selected direction (Gould and Gould 2012). It has long been recognized that uncovering the mechanisms of these decisions could provide valuable insight into the movements of fish (and thus species distributions, variability in catch, etc.) (Neave 1964; Royce et al. 1968; Harden-Jones 1968). Determining the sensory basis of marine migrations is obviously challenging (Hays et al. 2016), however studies in species that spend part of their lives in terrestrial habitats have proven quite useful (Putman et al. 2017). Pacific salmon in particular have contributed substantially to what is now known about migration from the animal's perspective and point to an emerging picture that the use of cues from the Earth's magnetic field plays a central role (Quinn 2018).

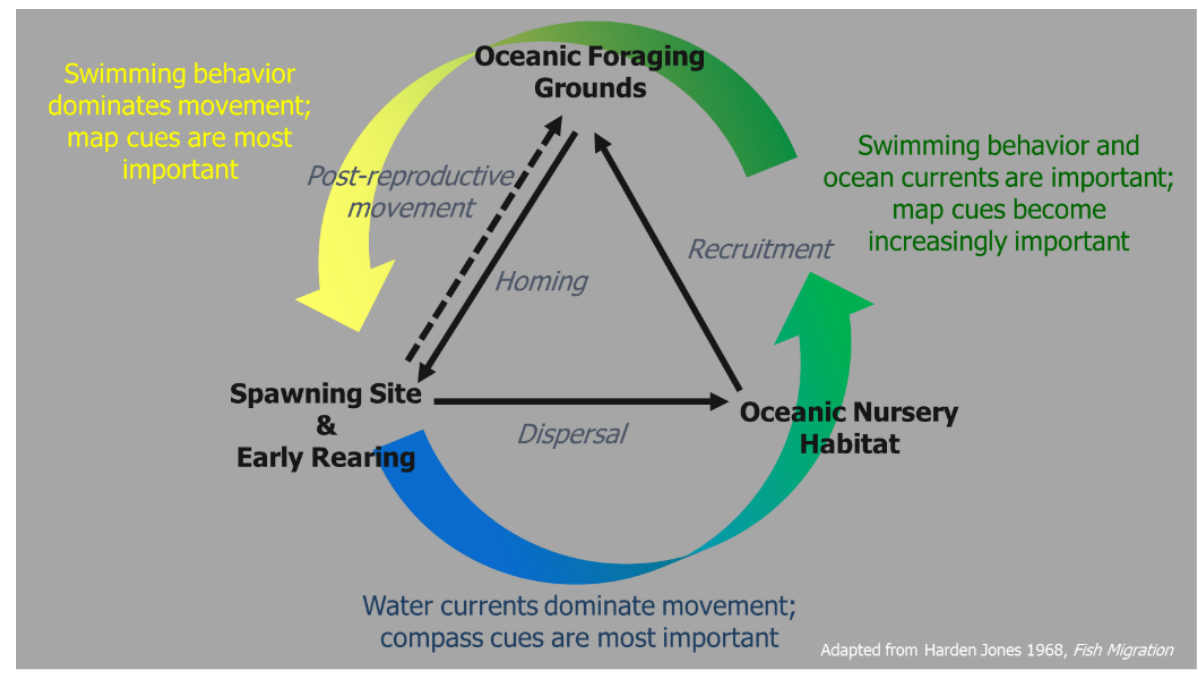

Fig. 1. The migration triangle of marine fishes (adapted from Harden Jones et al. 1968). The inner black arrows indicate ontogenetic shifts in habitat. The line for "Post-reproductive movement" is dashed to denote that not all species return to foraging grounds after spawning (notably, most Pacific salmonids do not). Outer arrows show the relative role of swimming behavior (yellower) and water currents (bluer) on the large-scale movements of fish during migration. The ability of animals to assess their position in the marine environment is an essential aspect of migratory life-histories, as it allows them to target potentially distant habitats that optimize growth and survival for a given life-stage, while still allowing them to return to previous locations that are more favorable for their offspring. For early life-stages, water currents dominate movement and because spawning typically occurs at particular sites where conditions facilitate juvenile dispersal, compass cues are sufficient to direct their journey. As fish age, swimming behavior becomes of equal importance to ocean currents and map cues are used to localize oceanic foraging grounds. For fish to return to their natal site to spawn, swimming behavior dominates movement and map cues are required for homing. 
Pacific salmon hatch in freshwater streams and juveniles swim to sea, travelling to distant foraging areas for a few months to years before returning to their natal river to spawn (Quinn 2018). Over the past three decades, experimental evidence has accumulated that salmonids use magnetic cues to guide their movements throughout the entirety of their life-cycle. Carefully controlled experiments show that juvenile salmon out-migrating from lakes use the magnetic field to maintain their swimming direction towards the sea (Quinn 1980; Quinn and Brannon 1982). Likewise, at swim-up, the vertical movement of Chinook salmon is sensitive to changes in the magnetic field, whereby upward swimming is reduced when the vertical component of the magnetic field is inverted (Putman et al. 2018). Moreover, even the alignment of rainbow trout embryos within their eggs appears to be sensitive to the direction of an applied magnetic field (Formicki et al. 2019). In each of these cases salmon are using the direction of the magnetic field for compass information.

While a compass is a useful navigational tool the map is essential for "closing the migration triangle", i.e., allowing animals to maintain population structure and return to the vicinity of their natal site to reproduce (HardenJones 1968; Secor 2015). The use of Earth's magnetic field as a map has long been an attractive (but contentious) hypothesis (Viguier 1882; Gould 2011). Magnetic field strength (total field intensity) and the angle at which magnetic field lines intersect the Earth's surface (inclination angle) vary from the poles to the equator, such that an animal capable of sensing these aspects of the field could extract latitudinal information (Fig. 2). Furthermore, the gradients of intensity and inclination are not entirely parallel but form a bicoordinate grid whereby longitudinal information can also be discriminated (Putman et al. 2011). Much of the work on animal navigation and migration has focused on birds, but evidence for their use of a magnetic map has been slow in coming (Thorup and Holland 2009; Mouritsen 2018). The definitive evidence that birds use a magnetic map to orient has only recently been shown in Eurasian reed warblers (Kishkinev et al. 2015; Chernetsov et al. 2017). The use of magnetic maps was first shown in taxonomic groups that have received much less attention, loggerhead sea turtles (Lohmann and Lohmann 1994, 1996; Lohmann et al. 2001) and red-spotted newts (Fischer et al. 2001; Phillips et al. 2002). In the years that followed, use of a magnetic map has been conclusively shown in a diversity of species that undertake migrations in marine habitats: spiny lobsters (Boles and Lohmann 2003), green sea turtles (Lohmann et al. 2004), Chinook salmon (Putman et al. 2014a), steelhead trout (Putman et al. 2014b), European eel (Naisbett-Jones et al. 2017), and Atlantic salmon (Scanlan et al. 2018).
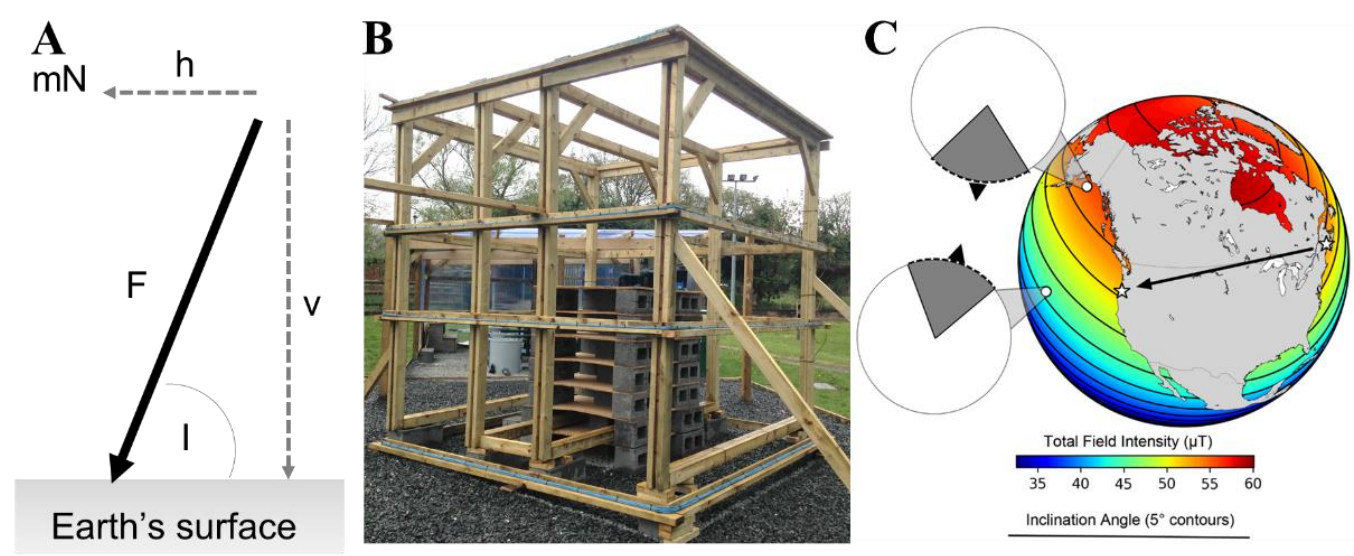

Fig. 2. (A) Earth's magnetic field can be described as a vector in which horizontal ("h") and vertical ("v") components of the field sum to the total field intensity ("F") and inclination angle ("I"). The direction of the horizontal component corresponds to magnetic north ("mN"). Total field intensity and inclination angle vary predictably over the surface of the Earth; increasing in strength and steepness towards the poles. However, these gradients are not entirely parallel and can thus provide animals information on both latitudinal and longitudinal position. (B) The orientation of animals to specific aspects of Earth's magnetic field can be investigated using a system of carefully spaced and wrapped coils of wire that are suspended from a non-magnetic frame and connected to a DC power supply. Changing the direction and amperage of electric current running through the wires allows animals at the center of the coil to be exposed to values of total field intensity and inclination angles that exist at sites distant to the testing location, i.e., "magnetic displacements." (C) A recent example of a magnetic displacement experiment shows that Atlantic salmon from a population in Maine, USA that were reared in Oregon, USA respond to a northern magnetic displacement by orienting to the south and respond to a southern magnetic displacement by orienting to the north (data from Scanlan et al. 2018). This differential response indicates an ability to detect map cues from the magnetic field, use it for orientation, and, apparently, correctly identify the direction of displacement. 
These studies make use of a technique known as "magnetic displacements", which provide a powerful way to (i) show that specific aspects of the magnetic field are perceptible to animals, (ii) demonstrate that the information is used for orientation, and (iii) provide ecological context for the sensory ability (Lohmann et al. 2007; Gould 2014; Putman 2018). Understandably, perhaps, an experimental approach that yields so much information at once is at times misunderstood by those with unfamiliarity with lab-based experimental design (e.g., Courtillot et al. 1997; Durif et al. 2017). To head-off such confusion in the salmon community, a brief explanation is warranted. In these experiments, individual animals are placed within orientation arenas within a system of orthogonally-aligned coiled wires; one set of coils is aligned along the north-south axis of the arena the other is aligned in the vertical plane. Electric current run through the wires from a DC power supply generates a magnetic field which adds to or subtracts from the vertical and horizontal component of the local magnetic field (depending upon the direction of electric current) (Figs. 2A, 2B). The strength of the generated field depends upon the amperage of the electric current. Larger coils allow a larger area of field uniformity and finer-scale control of the magnetic field but require higher electric current. This allows the experimenter to precisely manipulate the magnetic field intensity and inclination experienced by the animal, such as to recreate a magnetic field that exists at a distant location along the oceanic migratory route (Fig. 2C). In these experiments, the direction of magnetic north and other sources of information or noise are either held constant or randomized across trials. Thus, if orientation responses of a group of animals differs to two or more different magnetic displacements it can be unequivocally concluded that the animals perceive the magnetic change, use it for orientation, and thus possess a magnetic map (Lohmann et al. 2007; Gould 2014).

Use of a magnetic map has been most frequently discussed as a mechanism for homing. An enduring hypothesis is that of "geomagnetic imprinting": animals remember the magnetic field values at their natal site and use the predictable gradients of Earth's magnetic field as a kind of "map" to return upon reaching maturity. However, the best evidence for magnetic maps in marine animals (excluding, perhaps, lobsters (Boles and Lohmann 2003)) shows a rather different function, to guide the movements of juveniles to oceanic foraging grounds. Studies show that before the outset of smoltification salmon possess a magnetic map based on both intensity and inclination (Putman et al. 2014a). This map is independent of prior migratory experience, given that salmon that never left their hatchery respond to large-scale magnetic displacements (Putman et al. 2014a, b; Scanlan et al. 2018). The magnetic map is also independent of a recent evolutionary history of migration, in that it is conserved across anadromous and nonanadromous populations (Scanlan et al. 2018). Likewise, it appears to be a general solution for navigation, in the offspring of Atlantic salmon that were transported from Maine to Oregon, USA respond appropriately to magnetic displacements in the North Pacific (Fig. 2C) (Scanlan et al. 2018). Such an ability appears possible because the orientation responses of juvenile salmon can be modified depending upon the magnetic conditions they experience during early rearing. Steelhead trout raised in a spatially inhomogeneous magnetic field (owing to the iron infrastructure associated with the hatchery) did not differentiate a north/south magnetic displacement, whereas those raised under more natural magnetic conditions could (Putman et al. 2014b). Finally, the orientation responses to magnetic displacements observed in the lab appear to be highly adaptive to juvenile fish during their oceanic migration to foraging grounds. Simulating this behavior in an ocean circulation model showed that it facilitates (i) movement into and retention within favorable thermal habitat, (ii) group cohesion and schooling, and (iii) following a more predictable migration route over successive generations (Putman 2015).

Magnetic displacements combined with computer simulations provide a glimpse into the largely unknown migration of juveniles to marine foraging grounds. Major questions in salmon ecology and management are related to this period of the salmon life-cycle and the information afforded by this work allows specific, process-based and testable predictions on spatiotemporal variation in individual movements, population distributions (stock structure), migratory routes, return strength, homing/straying, hatchery (and escaped farmed)/wild interactions, and responses to changing climate. Indeed, the value of understanding how salmon use magnetic cues is beginning to emerge. For instance, the routes of two adult chum salmon tracked from the North Pacific to coastal Japan using light-level geolocators and tri-axial magnetometers appear consistent with the use of magnetic map cues (Azumaya et al. 2016). At the population level, the migratory routes (and relative proportion of fisheries catch) of sockeye and pink salmon homing to the Fraser River appears related to their use of a magnetic map for navigation (Putman et al. 2013; 2014c). Annual variation in the proportion of sockeye and pink salmon that return to the Fraser River via the Queen Charlotte Strait (northern route) vs. the Strait of Juan de Fuca (southern route) from the 1950s to present is better explained by gradual drift of the geomagnetic field than changes in ocean temperatures, currents, or river outflow (Putman et al. 2014c). These studies suggest that explicitly considering the interaction between salmon and their environment, as mediated by their use of magnetic cues to navigate, could improve predictions of shifting distribution and abundance in response to changing conditions (Putman 2018).

The work to-date could be interpreted as lines of evidence for the overriding importance of magnetic cues for salmon to complete their life-cycle. The findings that salmon possess a magnetic map and are sensitive to magnetic 
cues very early in life are consistent with the hypothesis that salmon imprint on magnetic field values as juveniles and recall them later as adults to complete their long-distance migration (Lohmann et al. 2008a; Bracis and Anderson 2012; Lohmann and Lohmann 2019). However, as with any laboratory experiment or correlational analysis (which includes tracking experiments), room for skepticism remains (Lohmann et al. 2008b; Putman et al. 2014c). Fortunately, the geomagnetic imprinting hypothesis could be rigorously tested by a large-scale field experiment in which fish of the same population are reared in magnetic fields that correspond to different locations along the coast and subsequently released. If salmon use magnetic cues for homing, the fish would be putatively "programmed" to return to those sites, rather than the geographic site of rearing. Differential marking of groups (external marking in addition to genetic parentage analyses) and coordination with fishers would allow for a clear test of predictions. Acoustic tagging a subset of smolts and tracking their initial movements along the acoustic arrays of Oregon, Washington, and British Columbia (Payne et al. 2010) would allow further assessments of at what point groups begin to diverge. Stable isotope analyses of returning fish (Volk et al. 2010) could also provide insight into other ecological implications of differential imprinting. The definitive evidence for geomagnetic imprinting in salmon would move us towards a process-based understanding of salmon ecology that could greatly benefit hatchery production practices, forecasting salmon returns, and predicting salmonid responses to environmental change (Putman 2018).

\section{REFERENCES}

Azumaya, T., S. Sato, S. Urawa., and T. Nagasawa. 2016. Potential role of the magnetic field on homing in chum salmon (Oncorhynchus keta) tracked from the open sea to coastal Japan. N. Pac. Anadr. Fish Comm. Bull. 6: 235-241. (Available at https://npafc.org)

Boles, L.C., and K.J. Lohmann. 2003. True navigation and magnetic maps in spiny lobsters. Nature. 42: 60-63.

Bracis, C., and J.J. Anderson. 2012. An investigation of the geomagnetic imprinting hypothesis for salmon. Fish. Oceanogr. 21(2-3): 170-181.

Chernetsov, N., A. Pakhomov, D. Kobylkov, D. Kishkinev, R.A. Holland, and H. Mouritsen. 2017. Migratory Eurasian reed warblers can use magnetic declination to solve the longitude problem. Curr. Biol. 27(17): 2647-2651.

Courtillot, V., G. Hulot, M. Alexandrescu, J.L. le Mouë, and J.L. Kirschvink. 1997. Sensitivity and evolution of sea-turtle magnetoreception: observations, modelling and constraints from geomagnetic secular variation. Terra Nova. 9(5-6): 203-207.

Durif, C.M., S. Bonhommeau, C. Briand, H.I. Browman, M. Castonguay, F. Daverat, W. Dekker, E. Diaz, R. Hanel, M.J. Miller, and A. Moore. 2017. Whether European eel leptocephali use the Earth's magnetic field to guide their migration remains an open question. Curr. Biol. 27(18): 998-1000.

Fischer, J.H., M.J. Freake, S.C. Borland, and J.B. Phillips. 2001. Evidence for the use of magnetic map information by an amphibian. Anim. Behav. 62(1): 1-10.

Formicki, K., A. Korzelecka-Orkisz, and A. TaŃski. 2019. Magnetoreception in fish. J. Fish Biol. 95: 73-91.

Gould, J.L., and C.G. Gould. 2012. Nature's compass: the mystery of animal navigation (Vol. 16). Princeton University Press. 320 pp.

Gould, J.L. 2011. Animal navigation: longitude at last. Curr. Biol. 21(6): 225-227.

Gould, J.L. 2014. Animal navigation: a map for all seasons. Curr. Biol. 24(4):153-155.

Harden-Jones, F.R. 1968. Fish Migration (London: Arnold).

Hays, G.C., L.C. Ferreira, A.M. Sequeira, M.G. Meekan, C.M. Duarte, H. Bailey, F. Bailleul, W.D. Bowen, M.J. Caley, D.P. Costa, and V.M. Eguíluz. 2016. Key questions in marine megafauna movement ecology. Trends in Ecol. Evol. 31(6): 463-475.

Kishkinev, D., N. Chernetsov, A. Pakhomov, D. Heyers, and H. Mouritsen. 2015. Eurasian reed warblers compensate for virtual magnetic displacement. Curr. Biol. 25(19): 822-824.

Lohmann, K.J., and C.M.F. Lohmann. 1994. Detection of magnetic inclination angle by sea turtles: a possible mechanism for determining latitude. J. Exp. Biol. 194(1): 23-32.

Lohmann, K.J., and C.M.F. Lohmann. 1996. Detection of magnetic field intensity by sea turtles. Nature. 380: 5961.

Lohmann, K.J., and C.M.F. Lohmann. 2019. There and back again: natal homing by magnetic navigation in sea turtles and salmon. J. Exp. Biol. 222(1): jeb184077.

Lohmann, K.J., S.D. Cain, S.A. Dodge, and C.M.F. Lohmann. 2001. Regional magnetic fields as navigational markers for sea turtles. Science. 294(5541): 364-366. 
Lohmann, K.J., C.M.F. Lohmann, and C.S, Endres. 2008b. The sensory ecology of ocean navigation. J. Exp. Biol. 211(11): 1719-1728.

Lohmann, K.J., C.M.F. Lohmann, and N.F. Putman. 2007. Magnetic maps in animals: nature's GPS. J. Exp. Biol. 210(21): 3697-3705.

Lohmann, K.J., C.M.F. Lohmann, L.M. Ehrhart, D.A. Bagley, and T. Swing. 2004. Animal behaviour: geomagnetic map used in sea-turtle navigation. Nature. 428(6986): 909-910.

Lohmann, K.J., N.F. Putman, and C.M.F. Lohmann. 2008. Geomagnetic imprinting: A unifying hypothesis of long-distance natal homing in salmon and sea turtles. Proc. Nat. Acad. Sci. USA. 105(49): 19096-19101.

Mouritsen, H. 2018. Long-distance navigation and magnetoreception in migratory animals. Nature. 558(7708): $50-59$.

Naisbett-Jones, L.C., N.F. Putman, J.F. Stephenson, S. Ladak, and K.A. Young. 2017. A magnetic map leads juvenile European eels to the Gulf Stream. Curr. Biol. 27(8): 1236-1240.

Neave, F. 1964. Ocean migrations of Pacific salmon. J. Fish. Res. Board Can. 21: 1227-1244.

Payne, J., K. Andrews, C. Chittenden, G. Crossin, F. Goetz, S.G. Hinch, P. Levin, S.T. Lindley, S. McKinley, M.C. Melnychuk, and T. Nelson. 2010. Tracking fish movements and survival on the Northeast Pacific Shelf. Blackwell Publishing Ltd, Oxford. pp. 267-290 pp.

Phillips, J.B., M.J. Freake, J.H. Fischer, and C.S. Borland. 2002. Behavioral titration of a magnetic map coordinate. J. Comp. Physiol. A. 188(2): 157-160.

Putman, N.F. 2015. Inherited magnetic maps in salmon and the role of geomagnetic change. Integr. Comp. Biol. 55(3): 396-405.

Putman, N.F. 2018. Marine migrations. Curr. Biol. 28(17): 972-976.

Putman, N.F., C.S. Endres, C.M.F. Lohmann, and K.J. Lohmann. 2011. Longitude perception and bicoordinate magnetic maps in sea turtles. Curr. Biol. 21(6): 463-466.

Putman, N.F., E.S. Jenkins, C.G. Michielsens, and D.L. Noakes. 2014c. Geomagnetic imprinting predicts spatiotemporal variation in homing migration of pink and sockeye salmon. J. R. Soc. Interface. 11(99): 20140542.

Putman, N.F., K.J. Lohmann, E.M. Putman, T.P. Quinn, A.P. Klimley, and D.L. Noakes. 2013. Evidence for geomagnetic imprinting as a homing mechanism in Pacific salmon. Curr. Biol. 23(4): 312-316.

Putman, N.F., Meinke, A.M. and Noakes, D.L., 2014b. Rearing in a distorted magnetic field disrupts the 'map sense' of juvenile steelhead trout. Biol. Letters. 10(6): 20140169.

Putman, N.F., M.M. Scanlan, E.J. Billman, J.P. O’Neil, R.B. Couture, T.P. Quinn, K.J. Lohmann, and D.L. Noakes. 2014a. An inherited magnetic map guides ocean navigation in juvenile Pacific salmon. Curr. Biol. 24(4): 446-450.

Putman, N.F., M.M. Scanlan, A.M. Pollock, J.P. O'Neil, R.B. Couture, J.S. Stoner, T.P. Quinn, K.J. Lohmann, and D.L. Noakes. 2018. Geomagnetic field influences upward movement of young Chinook salmon emerging from nests. Biol. Letters. 14(2): 20170752.

Quinn, T.P., and E.L. Brannon. 1982. The use of celestial and magnetic cues by orienting sockeye salmon smolts. J. Comp. Physiol. A. 147(4): 547-552.

Quinn, T.P. 1980. Evidence for celestial and magnetic compass orientation in lake migrating sockeye salmon fry. J. Comp. Physiol. 137(3): 243-248.

Quinn, T.P. 2018. The behavior and ecology of Pacific salmon and trout, second edition. Univ Washington Press, Seattle.

Royce, W.F., Smith, L.S., and Hartt, A.C. 1968. Models of oceanic migrations of Pacific salmon and comments on guidance mechanisms. Fish Bull. 66: 441-462.

Scanlan, M.M., Putman, N.F., Pollock, A.M. and Noakes, D.L., 2018. Magnetic map in nonanadromous Atlantic salmon. Proc. Nat. Acad. Sci. USA. 115(43): 10995-10999.

Secor, D.H. 2015. Migration ecology of marine fishes. JHU Press.

Thorup, K., and R.A. Holland. 2009. The bird GPS-long-range navigation in migrants. J. Exp. Biol. 212(22): 3597-3604.

Viguier, C. 1882. Le sens de l'orientation et ses organes chez les animaux et chez l'homme. Rev. Phil. France Etranger 14: 1-36. 